\title{
Ten year mortality in subsets of patients with an acute coronary syndrome
}

\author{
J Herlitz, B W Karlson, M Sjölin, J Lindqvist
}

\begin{abstract}
Objective-To describe the mortality during the subsequent 10 years for subsets of patients hospitalised for suspected acute coronary syndrome.

Patients and methods-All patients who were admitted to the emergency department in one hospital during 21 months for chest pain or other symptoms raising suspicion of an acute coronary syndrome were registered. From this baseline population three subgroups were defined among those being hospitalised: patients who developed a $\mathrm{Q}$ wave acute myocardial infarction (AMI) ( $\mathrm{n}=306)$; patients who developed a non- $\mathrm{Q}$ wave AMI ( $\mathrm{n}=527)$; and patients who developed confirmed or possible myocardial ischaemia (unstable angina pectoris) $(n=1274)$. These three groups were compared in terms of 10 year mortality.

Results-Patients who developed a non-Q wave AMI had the highest 10 year mortality (70.3\%), significantly higher than those who developed a Q wave AMI $(60.1 \% ; \mathrm{p}=0.004)$ and those who had confirmed or possible myocardial ischaemia $(50.1 \%$; $<0.0001)$. There was no difference between patients with confirmed and those with possible myocardial ischaemia $(50.0 \%$ and $50.1 \%$, respectively). After correction for dissimilarities in age, sex, and history the adjusted risk ratio for death in patients with a non-Q wave AMI compared with Q wave AMI was 1.01 (95\% confidence interval (CI) 0.82 to 1.25 ). The corresponding risk ratio for death in patients with a non-Q wave AMI compared with confirmed or possible myocardial ischaemia was 1.91 (95\% CI 1.64 to 2.23 ). There was also an imbalance in drug regimens among groups.

Conclusion-This study shows that in a non-selected population of patients hospitalised with a suspected acute coronary syndrome, the highest risk of death is found in those with a non-Q wave AMI and the lowest in those with confirmed or possible myocardial ischaemia. Thus, patients with a $\mathrm{Q}$ wave $\mathrm{AMI}$ have a long term mortality risk intermediate between the two fractions defined as having unstable coronary artery disease. However, adjusting these results for age and history of cardiovascular disease eliminated the observed difference in mortality between non-Q wave and $Q$ wave AMI. Furthermore, an imbalance in drug regimens might have affected the outcome.

(Heart 2001;86:391-396)
\end{abstract}

Keywords: prognosis; acute coronary syndrome

A large proportion of patients admitted to hospital for symptoms of acute chest pain suffer from a suspected or confirmed acute coronary syndrome. These patients usually are divided into two groups: those with a $\mathrm{Q}$ wave acute myocardial infarction (AMI) and those with unstable coronary artery disease.

The latter group can be further divided into two subgroups: those with a non-Q wave AMI and those with unstable angina pectoris. ${ }^{1-3}$ Although this subdivision from a pathophysiological point of view seems reasonable, we have no clear information on whether the long term prognosis differs in these subsets of patients and, if so, in what respect.

This survey evaluated the 10 year prognosis in a representative population of patients hospitalised with symptoms interpreted as being caused by either a confirmed or a suspected acute coronary syndrome.

Patients were divided into three subsets: those with a $\mathrm{Q}$ wave $\mathrm{AMI}$, those with a non-Q wave AMI, and those with confirmed or possible myocardial ischaemia.

\section{Patients and methods}

The aim of the present study was to relate the long term prognosis among patients hospitalised and given a diagnosis equivalent to a suspected or confirmed acute coronary syndrome to whether their condition was diagnosed as Q wave AMI, non-Q wave AMI, or myocardial ischaemia.

The primary end point was total mortality over 10 years. Secondary end points were cardiovascular and cardiac mortality over 10 years.

Sahlgrenska University Hospital in Göteborg, Sweden serves a population of 241000 inhabitants in an area of $342 \mathrm{~km}^{2}$.

All patients who came to the emergency department between 15 February 1986 and 9 November 1987 with chest pain or other symptoms indicative of AMI were registered consecutively. All patients, with the exception of eight who died in the emergency department, were included in the analyses.

We classified the reasons for admission to the emergency department as one or more of the following: chest pain, acute heart failure, arrhythmia, loss of consciousness, or "unspecific symptoms". Unspecific symptoms were, for example, severe hypotension, ECG signs of AMI, and laboratory data suggestive of infarction.

On the basis of history, clinical examination, and a standard 12 lead ECG recorded soon after admission, all patients were classified by the physician on duty in the emergency department into one of the following four categories: 
Table 1 Distribution of patients hospitalised according to final diagnosis $(n=3515)$

\begin{tabular}{lcr}
\hline & Frequency & \multicolumn{1}{c}{$\%$} \\
\hline Confirmed AMI & 833 & 23.8 \\
Possible AMI & 213 & 6.1 \\
Myocardial ischaemia & 431 & 12.3 \\
Possible myocardial ischaemia & 843 & 24.1 \\
Pulmonary embolism & 48 & 1.4 \\
Pleuropneumonia & 79 & 2.3 \\
Gastritis & 106 & 3.0 \\
Pericarditis & 38 & 1.1 \\
Hepatobiliary disease & 26 & 0.7 \\
Musculoskeletal pain & 134 & 3.8 \\
Psychogenic pain & 106 & 3.0 \\
Other & 287 & 8.2 \\
Uncertain & 359 & 10.2 \\
\hline
\end{tabular}

- Obvious myocardial infarction: typical symptoms and ST segment elevation with or without Q waves on the ECG;

- Strongly suspected myocardial infarction: (a) typical symptoms but no ST elevation or Q waves on the ECG; (b) atypical symptoms but ST-T changes or Q waves on the ECG; (c) sudden onset of severe congestive heart failure without ST elevation or Q waves on the ECG; (d) unstable angina pectoris regardless of the ECG;

- Vague suspicion of myocardial infarction: difficulties in interpretation of the symptoms and no signs of acute ischaemia on the ECG;

- No suspected myocardial infarction: (a) no suspected ischaemic heart disease; (b) stable angina pectoris.

A standard 12 lead ECG was registered soon after admission to the emergency department and prospectively classified the following day into one of the following groups by an experienced member of our study group: (a) normal (no pathological signs); (b) pathological, but no signs of acute ischaemia (for example, old infarctions, bundle branch block, nonspecific ST-T changes); or (c) signs of acute ischaemia (ST elevation $\geqslant 2 \mathrm{~mm}$ in leads $\mathrm{V} 1-\mathrm{V} 4$ or $\geqslant 1 \mathrm{~mm}$ in aVL, aVF, I, II, III, or V5-V6, ST depression $\geqslant 1 \mathrm{~mm}, \mathrm{~T}$ wave inversion, $\mathrm{Q}$ wave $\geqslant 2 \mathrm{~mm}$ wide) in at least two leads.

DEFINITIONS

All final diagnoses were given one year after the admission to the emergency department and considered simultaneously the judgement in the emergency department and various clinical investigations during the year of follow up.

Table 2 Patient characteristics at base line

\begin{tabular}{|c|c|c|c|c|c|}
\hline & $\begin{array}{l}Q \text { wave } A M I \\
(n=306)\end{array}$ & $p$ Value & $\begin{array}{l}\text { Non- } Q \text { wave } \\
A M I(n=527)\end{array}$ & $p$ Value & $\begin{array}{l}\text { Myocardial } \\
\text { ischaemia } \\
(n=1274)\end{array}$ \\
\hline \multicolumn{6}{|l|}{ Age (years) } \\
\hline Mean (SD) & $68(11)$ & 0.003 & $71(12)$ & $<0.0001$ & $68(13)$ \\
\hline Range & $35-94$ & & $24-101$ & & $19-100$ \\
\hline \multicolumn{6}{|l|}{ Sex $(\%)$} \\
\hline Women & 32.4 & & 32.8 & $<0.0001$ & 44.6 \\
\hline Men & 67.6 & & 67.2 & & 55.4 \\
\hline \multicolumn{6}{|l|}{ History $(\%)$} \\
\hline Myocardial infarction (9)^ & 10.9 & $<0.0001$ & 30.7 & & 29.4 \\
\hline Angina pectoris $(14)$ & 34.8 & 0.002 & 46.0 & $<0.0001$ & 57.8 \\
\hline Diabetes mellitus (10) & 7.9 & 0.013 & 13.8 & & 11.4 \\
\hline Hypertension (6) & 28.8 & 0.018 & 37.1 & & 32.8 \\
\hline Congestive heart failure (5) & 5.6 & $<0.0001$ & 22.3 & & 24.7 \\
\hline Smoking (107) & 43.0 & 0.026 & 34.7 & & 30.9 \\
\hline
\end{tabular}

* The number of patients with missing information is shown in parentheses. AMI, acute myocardial infarction.
For the diagnosis of a confirmed AMI, two of the following criteria had to be fulfilled: (a) chest pain lasting at least 15 minutes; (b) serum aspartate aminotransferase above the normal range in samples for at least two days, together with an increase in serum creatine kinase; in doubtful cases creatine kinase $\mathrm{MB}$ fraction was also considered; or (c) development of $\mathrm{Q}$ waves in at least two leads of the standard 12 lead ECG.

For the diagnosis of a possible AMI the patient had to have chest pain for at least 15 minutes and at least one of the following: (a) only one serum aspartate aminotransferase measurement above the normal range together with an increase in serum creatine kinase; (b) an increase in serum creatine kinase with a normal serum aspartate aminotransferase concentration; or (c) development of a $\mathrm{Q}$ wave in only one lead on the standard 12 lead ECG.

The diagnosis of myocardial ischaemia was based on symptoms and one of the following ECG patterns in at least two leads on the standard 12 lead ECG: (a) development of ST depression $\geqslant 1 \mathrm{~mm}$; (b) development of ST elevation $\geqslant 1 \mathrm{~mm}$; or (c) development of $\mathrm{T}$ wave inversion.

If there were no ECG changes but there was a clinical suspicion of ischaemic heart disease as the cause of the symptoms, the patient was classified as having suspected myocardial ischaemia.

Congestive heart failure was present if there were clinical or radiological signs of congestive heart failure. Severe ventricular arrhythmia was defined as either ventricular fibrillation or treated ventricular tachycardia (associated with complication or with a duration $\geqslant 60 \mathrm{~s}$ ). High degree atrioventricular block was registered if second or third degree atrioventricular block appeared.

Mode of death was defined based on information from medical journals, necropsy reports, and death certificates.

For follow up, information on death was available from the national registry of deaths. All patients who were reported to be alive at one year and five years were approached through a postal inquiry to evaluate whether they had been revascularised. For those who had died all hospital records were evaluated to find out whether they had been revascularised.

CLASSIFICATION OF DEATH

Cardiac death was defined as death caused by a heart disease, where ischaemic heart disease was the most common cause. Other causes were various types of heart failure not related to ischaemic heart disease but caused by hypertension, valvar heart disease, or another undefined cause.

Cardiovascular death included cardiac death plus vascular death (pulmonary embolism, cerebrovascular death, death caused by a ruptured aortic aneuysm, and peripheral embolism).

STATISTICAL METHODS

Pitman's non-parametric test was used. In the evaluation of proportions Fisher's exact test, which is a special form of Pitman's test, was 
used. ${ }^{4}$ A probability value of $\mathrm{p}<0.05$ was regarded as significant. In the multivariate analysis, Cox proportional hazard regression analysis was used. All variables listed in table 1 were entered into the model. The estimation of adjusted risk ratio for death between patients with non-Q wave and those with $\mathrm{Q}$ wave $\mathrm{AMI}$ only, including those discharged from hospital, considered variables in tables 1 and 2 that differed between groups $(p<0.05)$. Probability values are shown in the tables if $\mathrm{p}<0.05$.

\section{Results}

In all, 5362 patients made 7157 visits to the emergency department because of acute chest pain or other symptoms raising suspicion of AMI during the 21 month registration period. Of all 7157 patient visits, 4690 (65.5\%) resulted in hospitalisation. During the first hospitalisation in these patients $(n=3515)$ $306(8.7 \%)$ developed a Q wave AMI during the first three days in hospital, $527(15.0 \%)$ developed a non-Q wave AMI, and 1274 $(36.2 \%)$ were judged as having confirmed or possible myocardial ischaemia as the cause of their symptoms.

In this study these three cohorts were compared in terms of characteristics and outcome. Among the remaining patients who were not included in this survey, $213(6.1 \%)$ were classified as having a possible AMI and

Table 3 ECG pattern on admission to hospital

\begin{tabular}{|c|c|c|c|c|c|}
\hline & $\begin{array}{l}Q \text { wave } A M I \\
(n=306)\end{array}$ & $p$ Value & $\begin{array}{l}\text { Non- } Q \text { wave } \\
A M I(n=524) *\end{array}$ & $p$ Value & $\begin{array}{l}\text { Myocardial } \\
\text { ischaemia } \\
(n=1267) \dagger\end{array}$ \\
\hline Normal ECG & 4.9 & $<0.0001$ & 12.8 & $<0.0001$ & 37.8 \\
\hline $\begin{array}{l}\text { Pathological ECG but no } \\
\text { acute ischaemia }\end{array}$ & 5.9 & $<0.0001$ & 35.3 & $<0.0008$ & 44.0 \\
\hline Acute myocardial ischaemia & 89.2 & $<0.0001$ & 52.1 & $<0.0001$ & 18.3 \\
\hline ST elevation & 73.2 & $<0.0001$ & 25.2 & $<0.0001$ & 1.4 \\
\hline ST depression & 32.0 & 0.001 & 23.8 & $<0.0001$ & 8.8 \\
\hline $\mathrm{T}$ wave inversion & 19.0 & & 14.7 & 0.002 & 9.5 \\
\hline $\mathrm{Q}$ wave & 36.0 & $<0.0001$ & 6.1 & $<0.0001$ & 0.4 \\
\hline
\end{tabular}

*Information missing in three patients.

†Information missing in seven patients.

Table 4 Complications in hospital

\begin{tabular}{llllc}
\hline & $\begin{array}{l}\text { Q wave AMI } \\
(n=306)\end{array}$ & $\begin{array}{l}\text { Non-Q } \\
\text { wave AMI } \\
(n=527)^{*}\end{array}$ & p Value & $\begin{array}{c}\text { Myocardial } \\
\text { ischaemia } \\
(n=1274)\end{array}$ \\
\hline Congestive heart failure (\%) & 52.9 & 49.2 & $<0.0001$ & 23.8 \\
Severe ventricular arrhythmia (\%) & 7.2 & 5.0 & $<0.0001$ & 0.9 \\
High degree AV block (\%) & 3.9 & 2.5 & 0.019 & 0.8 \\
Hypotension requiring inotropic agents (\%) & 9.5 & 9.6 & $<0.0001$ & 0.7 \\
\hline
\end{tabular}

${ }^{\star}$ Missing information in seven patients $(1 \%)$

†Missing information in 210 patients $(16 \%)$

Table 5 Medication prescribed at hospital discharge

\begin{tabular}{|c|c|c|c|c|c|}
\hline & $\begin{array}{l}Q \text { wave } A M I \\
(n=254)\end{array}$ & p Value & $\begin{array}{l}\text { Non- } Q \text { wave } \\
A M I(n=434)\end{array}$ & $p$ Value & $\begin{array}{l}\text { Myocardial } \\
\text { ischaemia } \\
(n=1251)\end{array}$ \\
\hline$\beta$ Blockers & 72.4 & 0.045 & 64.8 & $<0.0001$ & 40.8 \\
\hline Calcium channel blockers & 6.5 & & 11.4 & 0.0008 & 18.8 \\
\hline Long acting nitrates & 16.7 & 0.013 & 25.3 & 0.049 & 30.7 \\
\hline Diuretics & 49.0 & & 48.8 & 0.0001 & 37.3 \\
\hline Digitalis & 11.8 & 0.018 & 19.1 & & 22.2 \\
\hline Antiarrhythmics & 2.4 & & 1.8 & & 3.2 \\
\hline Anticoagulants & 20.8 & 0.009 & 12.7 & & 8.4 \\
\hline Lipid lowering drugs & 0.4 & & 0.5 & & 0.4 \\
\hline Aspirin & 16.3 & & 12.0 & & 9.6 \\
\hline ACE inhibitors & 4.1 & & 3.0 & & 2.0 \\
\hline Psychotropic drugs & 2.0 & & 3.2 & $<0.0001$ & 9.4 \\
\hline
\end{tabular}

ACE, angiotensin converting enzyme.
$1183(33.7 \%)$ as having causes of their symptoms other than possible or confirmed myocardial infarction or ischaemia. Information on aetiology was missing in 12 patients $(0.3 \%)$.

Table 1 shows the distribution of the aetiology of symptoms among all patients admitted to hospital.

Among patients with Q wave AMI, 87\% were admitted directly to the coronary care unit. Sixty three per cent of patients with non-Q wave AMI and $42 \%$ of patients with myocardial ischaemia were admitted directly to the coronary care unit.

BASELINE CHARACTERISTICS

Compared with patients with $\mathrm{Q}$ wave $\mathrm{AMI}$, those with a non-Q wave AMI were older and had a higher prevalence of previous myocardial infarction, angina pectoris, diabetes, hypertension, and congestive heart failure, but a lower prevalence of smoking (table 2). Compared with patients with confirmed or possible myocardial ischaemia, those with non- $Q$ wave AMI were older, were less likely to be women, and had a lower prevalence of angina pectoris.

INITIAL ECG PATTERN

The distribution of patients according to the initial ECG pattern differed notably, as expected, among the three groups (table 3 ).

COMPLICATIONS IN HOSPITAL

No significant difference was found between patients with a $\mathrm{Q}$ wave $\mathrm{AMI}$ and those with a non-Q wave AMI (table 4). Patients with a non-Q wave AMI more frequently developed congestive heart failure, severe ventricular arrhythmias, high degree atrioventricular block, and hypotension than patients with confirmed or possible myocardial ischaemia.

REVASCULARISATION

During the first five years after hospital admission $9.5 \%$ of patients with a $\mathrm{Q}$ wave $\mathrm{AMI}$, $10.4 \%$ of patients with a non-Q wave AMI, and $9.3 \%$ of patients with myocardial ischaemia underwent coronary artery bypass grafting (CABG). The corresponding figures for percutaneous transluminal coronary angioplasty (PTCA) were $1.6 \%, 1.7 \%$, and $3.4 \%$, respectively. Fibrinolytic drugs in the early phase were given to only $6.5 \%$ of patients with a $\mathrm{Q}$ wave AMI, $2.9 \%$ of patients with a non-Q wave $\mathrm{AMI}$, and $1.2 \%$ of patients with myocardial ischaemia.

\section{PRESCRIPTION OF MEDICATION AT HOSPITAL} DISCHARGE

Among patients discharged from hospital, those with a $Q$ wave AMI were more frequently prescribed $\beta$ blockers and anticoagulants and less frequently long acting nitrates and digitalis than patients with a non-Q wave AMI (table 5). Patients with a non-Q wave AMI were more frequently prescribed $\beta$ blockers and diuretics and less frequently calcium channel blockers, long acting nitrates, and psychotropic drugs than patients who had myocardial ischaemia. 


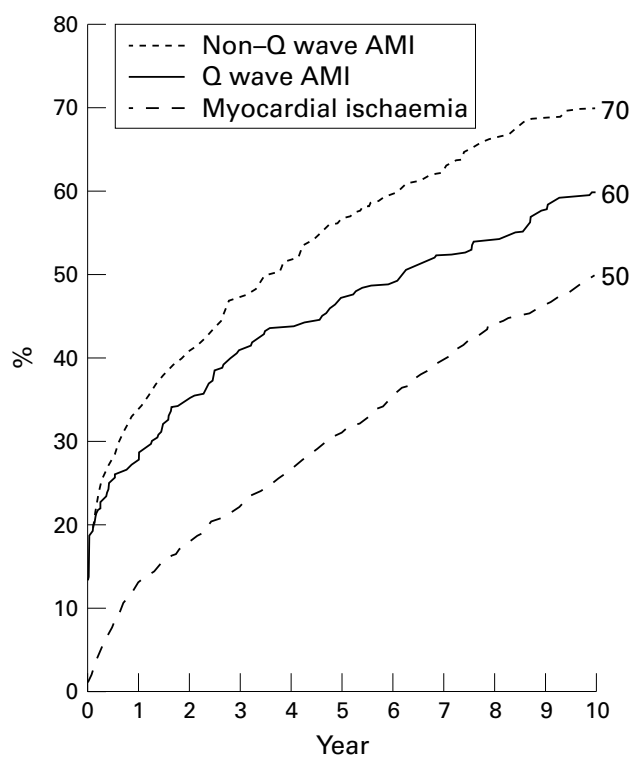

Figure 1 Ten year mortality among patients with $Q$ wave acute myocardial infarction ( $A M I)$, non- $Q$ wave $A M I$, and myocardial ischaemia.

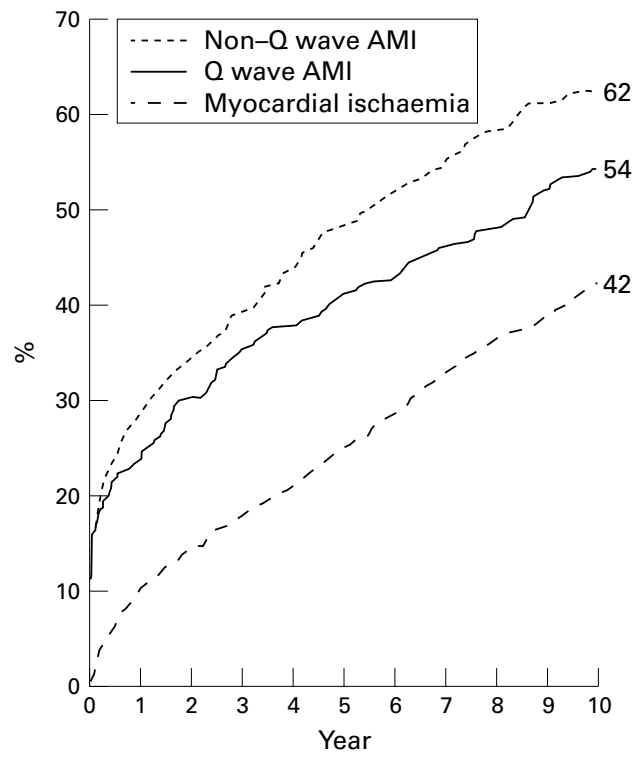

Figure 2 Ten year mortality among patients $<80$ years with $Q$ wave $A M I$, non- $Q$ wave $A M I$, and myocardial ischaemia.

MORTALITY

Information on 10 year mortality was available in $97 \%$ of patients with Q wave AMI, in $97 \%$ of patients with a non-Q wave AMI, and in $95 \%$ of patients with confirmed or possible myocardial ischaemia.

Table 6 Ten year mortality in relation to ECG pattern on admission to hospital

\begin{tabular}{llll}
\hline & $\begin{array}{l}\text { Q wave AMI } \\
(n=296)\end{array}$ & $\begin{array}{l}\text { Non-Q wave } \\
\text { AMI }(n=509)\end{array}$ & $\begin{array}{l}\text { Mycardial } \\
\text { ischeamia } \\
(n=1205)\end{array}$ \\
\hline $\begin{array}{l}\text { ECG pattern } \\
\quad \text { Normal }\end{array}$ & $4 / 13(30.8 \%)$ & $29 / 64(45.3 \%)$ & $124 / 462(26.8 \%)$ \\
$\quad$ Pathological but no acute ischaemia & $14 / 18(77.8 \%)$ & $151 / 177(85.3 \%)$ & $354 / 514(68.9 \%)$ \\
Myocardial ischaemia & $160 / 265(60.4 \%)$ & $176 / 266(66.2 \%)$ & $120 / 223(53.8 \%)$ \\
$\quad$ ST elevation & $126 / 217(58.1 \%)$ & $86 / 128(67.2 \%)$ & $10 / 18(55.6 \%)$ \\
$\quad$ ST depression & $57 / 94(60.6 \%)$ & $86 / 122(70.5 \%)$ & $67 / 107(62.6 \%)$ \\
$\quad$ T wave inversion & $36 / 57(63.2 \%)$ & $51 / 77(66.2 \%)$ & $55 / 115(47.8 \%)$ \\
\hline
\end{tabular}

Data are number of dead patients/number of patients evaluated.
Table 7 Mode of death

\begin{tabular}{llll}
\hline & $\begin{array}{l}\text { Q wave } \\
\text { AMI }\end{array}$ & $\begin{array}{l}\text { Non-Q } \\
\text { wave AMI }\end{array}$ & $\begin{array}{l}\text { Myocardial } \\
\text { ischaemia }\end{array}$ \\
\hline All patients & & & \\
$\quad$ Cardiovascular death & 50 & 63 & 38 \\
$\quad$ Cardiac death & 48 & 58 & 31 \\
$\begin{array}{l}\text { Patients who died } \\
\quad \text { Cardiovascular death }\end{array}$ & 85 & 90 & 77 \\
$\quad$ Cardiac death & 81 & 84 & 63 \\
\hline
\end{tabular}

Since information on death was missing in $15 \%$ of patients, data are rounded off.

Of 296 patients with a Q wave AMI, 178 $(60.1 \%)$ died, of 509 patients with a non-Q wave AMI, $358(70.3 \%)$ died, and of 1205 patients with confirmed or possible myocardial ischaemia, 603 (50.0\%) died.

Patients with a non-Q wave AMI had a higher mortality than patients with a $\mathrm{Q}$ wave AMI ( $p=0.004)$ and patients with myocardial ischaemia $(\mathrm{p}<0.0001)$ (fig 1$)$.

In the subgroup of 256 patients aged less than 80 years and having a Q wave AMI, 139 $(54.3 \%)$ died, of the 387 patients with non-Q wave AMI, $242(62.5 \%)$ died, and of 992 patients with confirmed or possible myocardial ischaemia, $417(42.0 \%)$ died. Patients with a non-Q wave AMI still had a higher mortality than patients with $Q$ wave AMI $(p=0.046)$ and patients with myocardial ischaemia $(\mathrm{p}<0.0001)$ (fig 2).

Table 6 shows mortality in the three groups in relation to the initial ECG pattern. In all subsets the highest mortality was observed in patients who developed a non-Q wave AMI. Mortality tended to be slightly higher in patients with $\mathrm{Q}$ wave $\mathrm{AMI}$ in most subsets than in those with myocardial ischaemia.

Of those patients with confirmed myocardial ischaemia $50.0 \%$ died, and of those with possible myocardial ischaemia $50.1 \%$ died. Of those patients with possible AMI follow up data were available in $95 \%$ and their 10 year mortality was $62.6 \%$. Among patients with "other causes for symptoms" follow up data were available for $92 \%$ and their mortality was $41.8 \%$.

MULTIVARIATE ANALYSIS

The adjusted risk ratio for differences in age, sex, and history in patients with non-Q wave versus $Q$ wave AMI was 1.01 (95\% confidence interval (CI) 0.82 to 1.25 ). The corresponding risk ratio for patients with non-Q wave AMI versus myocardial ischaemia was 1.91 (95\% CI 1.64-2.23). For patients discharged from hospital, in terms of age, sex, history, and medication prescribed at discharge, adjusted risk ratio for death among patients with non-Q wave versus Q wave AMI was 1.06 (95\% CI 0.84 to 1.34 )

MODE OF DEATH

Information regarding death was available in $85 \%$ of all patients who died. Table 7 shows the proportion of all patients who were judged to have died of cardiovascular and cardiac causes in the three groups. These proportions are also given for those who died. 


\section{Discussion}

A large proportion of patients hospitalised for acute chest discomfort have a suspected acute coronary syndrome. Although many of these patients have objective evidence of myocardial necrosis or myocardial ischaemia, one can assume that among patients with unstable angina pectoris a large proportion have no objective indices of myocardial ischaemia or necrosis. This is why we also included patients with possible myocardial ischaemia in our analyses. An interesting observation was that patients with possible myocardial ischaemia had a long term prognosis very similar to that of patients with confirmed myocardial ischaemia.

This study has the advantage of being prospective in design and including all patients hospitalised with an initial suspicion of an acute coronary syndrome in a single hospital covering a well defined area. A large proportion of patients were not admitted to the coronary care unit. This is the situation for many hospitals that serve the total population in a well defined catchment area. Thus, our results are more representative of the total hospital population than is usually the case when only patients admitted to the coronary care unit or patients participating in randomised trials are included in the survey.

However, at the time of patient inclusion modern biochemical markers available today, such as the troponins and creatine kinase $\mathrm{MB}$ fraction mass, were not in routine use. Therefore, classification of patients as having non-Q wave AMI, myocardial ischaemia, or possible myocardial ischaemia might have differed slightly today. It has been suggested that with the introduction of the troponins the delineation between AMI and unstable angina pectoris would be less distinct. ${ }^{5}$

The most important finding in this survey, which as far as we know has not shown before, was that among patients with a confirmed or suspected acute coronary syndrome, the worst prognosis was for patients with a non-Q wave AMI. Of these patients more than two thirds $(70 \%)$ were dead within 10 years.

This should be compared with one previous report showing a 10 year mortality of $53 \%$ in a similar patient population. ${ }^{6}$ However, in that study, which was done in the other city hospital in Göteborg, only patients admitted to the coronary care unit were included in the analysis. The corresponding 10 year mortality for patients with unstable angina pectoris in that study was $36 \%$, compared with $50 \%$ in our survey. This difference is probably also explained by different selection criteria.

Both our own and the previously reported study $^{6}$ found a pronounced difference in outcome between patients with a non- $Q$ wave $\mathrm{AMI}$ and those with unstable angina pectoristhat is, confirmed or possible myocardial ischaemia.

Many previous studies have compared outcome between patients with a $Q$ wave and those with a non-Q wave AMI. The short term outcome has mostly been reported to be worse for patients with a $\mathrm{Q}$ wave AMI, ${ }^{7}$ whereas in a longer perspective, the prognosis has been reported to be quite similar regardless of whether $\mathrm{Q}$ waves developed. ${ }^{9-15}$ No previous study has described the outcome in a 10 year perspective.

We found that, in absolute terms, the mortality was $10 \%$ higher in patients with non- $Q$ wave $A M I$ than in those with a $Q$ wave AMI. However, this difference seemed to be entirely explained by the difference in risk factors-that is, greater age and a higher prevalence of previous cardiovascular diseases.

There was an imbalance among groups with regard to drug regimens at hospital discharge. We cannot rule out the possibility that this might have affected the outcome. However, we did not know for how long various medications at hospital discharge were continued.

Recent data indicate that in patients with unstable coronary artery disease the prognosis can be greatly improved by early revascularisation. ${ }^{16}$ In this survey the rate of revascularisation was low in terms of both CABG and PTCA. It is possible that a more frequent use of these procedures might have influenced the outcome in a favourable way. Furthermore, we do not know whether a more frequent use of aspirin, fibrinolytic agents, lipid lowering drugs, and angiotensin converting enzyme inhibitors might have altered the outcome more substantially in any of the subsets of patients studied. The overall mortality in this study must be regarded as high. However, this should be related to the fact that, in contrast to previous reports in this research area, the study population was non-selected-that is, they were totally representative of patients hospitalised for a suspected acute coronary syndrome.

Six per cent of patients were judged as having a possible AMI. These patients had a prognosis similar to those with confirmed AMI. These patients were not included in the comparison, since they formed an intermediate group between those defined as having confirmed AMI and those defined as having myocardial ischaemia. However, regardless of whether they had been included in the AMI group or in the myocardial ischaemia group, results did not differ substantially.

\section{LIMITATIONS OF THE STUDY}

This survey was initiated at a time when treatment routines in this patient population differed from the situation of today. Thus, at that time the use of PTCA and CABG was lower than today. Furthermore, various medications such as aspirin, fibrinolytic agents, angiotensin converting enzyme inhibitors, and lipid lowering drugs were used less than they are today. However, this should not be looked upon only as a disadvantage for the evaluation. With a lower use of these various interventions, there is a better opportunity to discuss the influence of various predictors in the initial phase on the very long term outcome.

\section{CONCLUSION}

This study showed that in a non-selected population of patients hospitalised with a suspected acute coronary syndrome, the highest risk of death is found in those with a non-Q 
wave AMI and the lowest in those with confirmed or possible myocardial ischaemia. Thus, patients with a $\mathrm{Q}$ wave $\mathrm{AMI}$ have a long term mortality risk intermediate between the two groups defined as having unstable coronary artery disease. However, the difference in long term mortality between patients with non- $\mathrm{Q}$ wave $\mathrm{AMI}$ and those with $\mathrm{Q}$ wave $\mathrm{AMI}$ was entirely explained by differences in age and history and not by the absence of $\mathrm{Q}$ waves. Furthermore, an imbalance in drug regimens might have affected the outcome.

1 American College of Cardiology/American Heart Association. ACC/AHA task force report: guidelines for the early management of patients with acute myocardial infarction. $\mathcal{F}$ Am Coll Cardiol 1988;56:249-92.

2 Antman E, Sacks D, Rifai N, et al. Time to positivity of a rapid bedside assay for cardiacspecific troponin-t: prognorapid bedside assay for cardiacspecific troponin-t: prognodial infarction (TIMI) 11A substudy. $7 \mathrm{Am}$ Coll Cardiol dial infarction

3 Theroux P, Fuster V. Acute coronary syndromes: unstable angina and non- $Q$ wave myocardial infarction. Circulation 1998;97:1195-206.

4 Bradley JV. Distribution-free statistical test. London: PrenticeHall, Inc, 1968:73-6.

5 Olatidoye AG, Wu AHB, Feng YJ, et al. Prognostic role of troponin $\mathrm{T}$ versus I in unstable angina for cardiac events with meta-analysis comparing published studies. Am $f$ Cardiol 1998;81:1405-10.

6 Abrahamsson P, Rosengren A, Dellborg M. Improved longterm prognosis for patients with unstable coronary syndromes 1988-1995. Eur Heart $\mathcal{F}$ 2000;21:533-9.
7 Thanavaro S, Krone R, Kleiger R, et al. In-hospital prognois of patients with first non-transmural and transmural infsis of patients with first non-transmu

8 Goodman S, Califf R, Sgarbossa E, et al. Mortality, morbidity, resource use and quality of life following $Q$ vs. non-Q wave infarction following thrombolytic therapy: a GUSTO substudy. [abstract] 7 Am Coll Cardiol 1997;31:490A.

9 Stone P, Raabde D, Jaffe A, et al for the MILIS Group. Prognostic significance of location and type of myocardial infarction: independent adverse outcome associated with anterior location. 7 Am Coll Cardiol 1988;11:453-63.

10 Nicod P, Gilpin E, Dittrich H, et al. Short and long-term clinical outcome after $\mathrm{Q}$ wave and non $\mathrm{Q}$-wave myocardial infarction in a large patient population. Circulation 1989;79:528-36.

11 Benhorin J, Moss A, Oakes D, et al. The prognostic significance of first myocardial infarction type (Q-wave vs. non-Q wave) and Q-wave location. F Am Coll Cardiol 1990;15: 1201-7.

12 Aguiir F, Younis L, Chaitman B, et al. Early and 1-year clinical outcome of patients evolving non-Q versus $Q$ wave myocardial infarction after thrombolysis (for the TIMI-II Investigators). Circulation 1995;91:2541-8.

13 Zareba W, Moss A, Raubertas R. Risk of subsequent cardiac events in stable convalescing patients after first non-Q wave and $\mathrm{Q}$ wave myocardial infarction: the limited role of noninvasive testing. Coron Artery Dis 1994;5:1009-18.

14 Krone R, Friedman E, Thanavaro S, et al. Long-term prognosis after first $\mathrm{Q}$ wave (transmural) or non-Q wave (nontransmural) myocardial infarction. Analysis of 593 patients. Am 7 Cardiol 1983;52:234.

15 Welty F, Mittleman MA, Lewis S, et al. Significance of location (anterior versus inferior) and type $(Q$ wave versus non-Q wave) of acute myocardial infarction in patients undergoing percutaneous transluminal coronary angioplasty for postinfarction ischemia. Am f Cardiol 1995;76:431-5.

16 FRISC II investigators. Invasive compared with noninvasive treatment in unstable coronary artery disease. Lancet 1999; 354:708-15.

\section{IMAGES IN CARDIOLOGY}

\section{An adult with congenital aortic coarctation}

A 34 year old woman, who had suffered from hypertension for 16 years, presented with systolic blood pressure up to $220 \mathrm{~mm} \mathrm{Hg}$ and diastolic blood pressure up to $120 \mathrm{~mm} \mathrm{Hg}$, accompanied by headaches, dizziness, and paraesthesia in both arms. Auscultation revealed an aortic systolic murmur with radiation to the back.

Doppler echocardiography showed a pressure gradient of $66 \mathrm{~mm} \mathrm{Hg}$ in the descending part of the aorta. The suspicion of congenital postductal aortic coarctation was confirmed by transoesophageal echocardiography. Because of the impression of a complex structure of the stenosis, magnetic resonance imaging (top) and dynamic three dimensional computed tomographic angiography (bottom) were performed preoperatively where a siphon-like $75 \%$ stenosis with pre- and poststenotic dilation of the aorta were clearly shown. Because of the complex structure of the stenosis, surgery instead of balloon dilatation was recommended. Intraoperatively, the minimal lumen diameter in the stenotic region was $3 \mathrm{~mm}$. A resection of the aorta was performed with an interposition of a Vascutek prosthesis. The patient recovered uneventfully and has no residual hypertension.

LAURENT HAEGELI PHILIPP WEISS THOMAS F LÜSCHER haegeli@post.harvard.edu
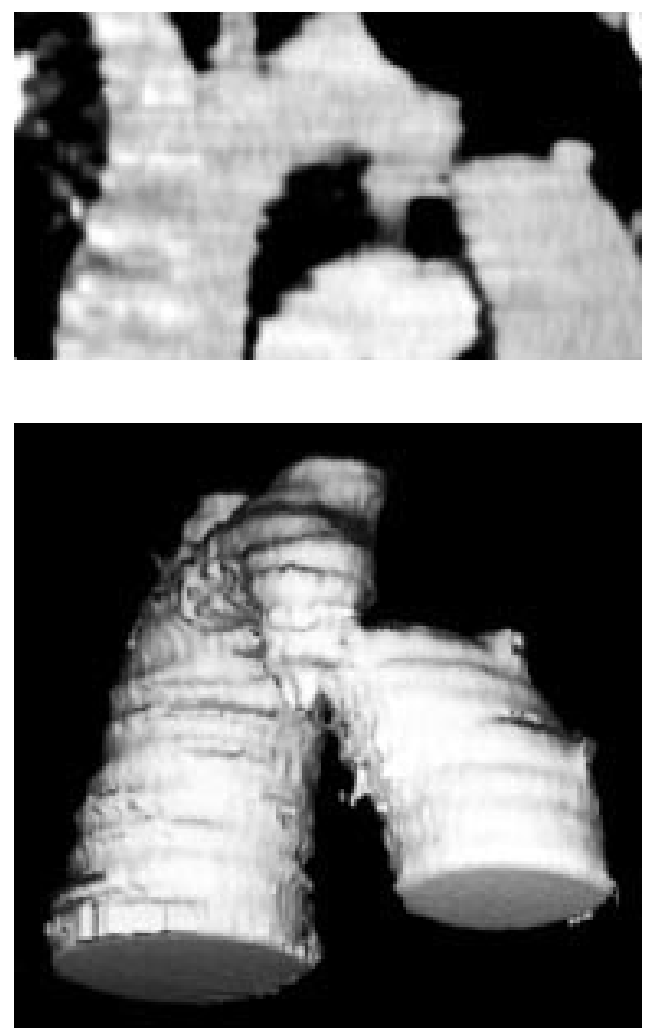